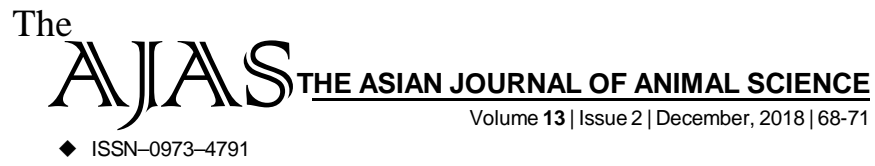

DOI : 10.15740/HAS/TAJAS/13.2/68-71 Visit us | www.researchjournal.co.in

RESEARCH ARTICLE.

\title{
Study on gross anatomy of male accessory sex glands in prepubertal and pubertal ram
}

\section{P.J. Kapadnis and P.N. Thakur}

Author for Corresponding -

\section{P.N. Thakur}

Department of Veterinary

Anatomy and Histology

College of Veterinary and Animal

Sciences, Parbhani (M.S.)

India

\begin{abstract}
The present research was conducted to study the gross anatomy of male accessory sex glands in prepubertal and pubertal ram. The length, width of the right and left ampulla in pubertal ram were more than the prepubertal ram. The right seminal vesicle was slightly larger than the left seminal vesicle in the same animal. Biometrical observations showed that there was on increase in the seminal veside dimensions in the pubertal as compared to prepubertal ram. The prostate gland was an unpaired more or less diffused and extended as greater difference along with technical part of the urethra under cover of urethral muscles. The prostate gland was present as pars diseminata only in prepubertal and pubertal ram. The bulbourethral glands were paired located on the dorsal surface of the bulbar portion of the pelvic part of the urethra. The gland in pubertal was relatively greater than the prepubertal.

KEY WORDS...... Gross anatomy, Ampulla, Prostate, Seminal vesicles bubourethral ram

HOW TO CITE THIS ARTICLE - Kapadnis, P.J. and Thakur, P.N. (2018). Study on gross anatomy of male accessory sex glands in prepubertal and pubertal ram. Asian J. Animal Sci., 13(2): 68-71. DOI : 10.15740/HAS/TAJAS/13.2/68-71. Copyright@2018: HindAgri-Horticultural Society.
\end{abstract}

ARTICLE CHRONICLE - Received : 08.08.2018; Revised : 10.11.2018; Accepted : 19.11.2018 